\title{
Does Examining the Childhood Food Experiences Help to Better Understand Food Choices in Adulthood?
}

\author{
Aleksandra Małachowska *(D) and Marzena Jeżewska-Zychowicz (ID \\ Department of Food Market and Consumer Research, Institute of Human Nutrition Sciences, Warsaw University \\ of Life Sciences (SGGW-WULS), Nowoursynowska 159C, 02-776 Warsaw, Poland; \\ marzena_jezewska_zychowicz@sggw.edu.pl \\ * Correspondence: aleksandra_malachowska@sggw.edu.pl; Tel.: +48-608-488-606
}

check for

updates

Citation: Małachowska, A.; Jeżewska-Zychowicz, M. Does Examining the Childhood Food

Experiences Help to Better

Understand Food Choices in Adulthood? Nutrients 2021, 13, 983. https://doi.org/10.3390/nu13030983

Academic Editors: Antonis Zampelas, George Moschonis and Emmanuella Magriplis

Received: 28 January 2021

Accepted: 16 March 2021

Published: 18 March 2021

Publisher's Note: MDPI stays neutral with regard to jurisdictional claims in published maps and institutional affiliations.

Copyright: (c) 2021 by the authors. Licensee MDPI, Basel, Switzerland. This article is an open access article distributed under the terms and conditions of the Creative Commons Attribution (CC BY) license (https:/ / creativecommons.org/licenses/by/ $4.0 /)$
Abstract: Impact of parental feeding practices on children's eating behaviors is well-documented in the literature. Nevertheless, little is known about how many of these behaviors might persist into adulthood. There is a lack of a tool measuring childhood feeding experiences recollected by adults, while the Comprehensive Feeding Practices Questionnaire (CFPQ) is used to measure parental feeding practices applied towards children. The aim of the study was to adapt the CFPQ to measure adults' recollections of their childhood (5-10 years old) feeding experiences, to examine its discriminant validity and then to assess if these practices are related to adults' food choices. In 2020, the modified version of CFPQ (mCFPQ) and questions on current food consumption were administered in a group of 500 adults twice over a two-week interval. The analysis included 443 participants whose questionnaires were correctly completed in both stages of the study. The Qsorting procedure was used to test for discriminant validity of the questionnaire, i.e., confirmatory and exploratory factor analysis (EFA), Cronbach's alpha, correlations coefficients, and the analysis of the differences between groups according to the intake of certain food products. Test-retest reliability was examined by calculating interclass correlation coefficients (ICC) for each obtained factor. As a result of EFA, five subscales were identified: "Restrictions", "Healthy Eating Guidance”, "Pressure and Food Reward", "Monitoring", and "Child Control". Items from these subscales created a new tool-Adults' Memories of Feeding in Childhood (AMoFiC). Test for internal consistency, factor correlations, and discriminant validity proved satisfactory psychometric parameters of AMoFiC. "Pressure and Food Reward" and "Child Control" were associated with higher intake of sweets and salty snacks, whereas "Healthy Eating Guidance", "Monitoring", and "Restrictions" were associated with higher consumption of fresh fruits and vegetables. Despite the fact that the AMoFiC questionnaire requires further research, the findings of the study might be of practical use in counseling addressed to the parents.

Keywords: parental feeding practices; childhood recollections; eating behavior; validation study

\section{Introduction}

Food preferences shaped at a young age might persist into adolescence and then into adulthood, hence childhood is perceived as a critical moment for the development of future eating behaviors [1]. Negative childhood feeding experiences might disturb children's sensitivity to internal hunger and satiety cues [2]. It may continue to have adverse impact and progress into maladaptive eating behaviors in adulthood, such as emotional eating [3,4].

In the family setting, a process of socialization based on the theory of social learning takes place [5]. Social learning is a mechanism in which environmental experiences, thus also those gathered in the family surroundings, are assimilated by an individual [6]. Parents, as major providers, models, and regulators in terms of food intake, influence children's eating in the greatest manner and in a variety of ways [7]. Parental feeding practices (PFP) are defined as goal-directed, food-, or eating-related strategies used by the parents 
to influence their children's eating manner, including what, when, and how much their child eats [8,9]. Studies have shown that PFP such as encouraging eating in a supportive manner, modeling favorable eating behaviors, eating meals together, and being responsive to children's hunger and satiety signals might favor healthy eating behaviors in children, including higher intake of fruit and vegetables [10-12], lower intake of low-nutrient-dense foods [13], and greater diet quality [14].

Association between PFP and eating behaviors is more commonly investigated in early (birth to 6 years) and middle (6 to 12 years) childhood [8,15-17], in comparison to adolescence $[18,19]$. Available studies $[3,4,20-24]$ indicate that childhood experiences might favor certain eating styles in adulthood (e.g., emotional eating, excessive food preoccupation, and disordered eating behaviors). However, there is a lack of research on the effect of PFP on food intake among young, middle-aged, and older adults $[3,24]$. Thus, the relationship between early feeding experiences, later eating behaviors, and food consumption still remains unclear and requires further examination [3]. Recognition of this association is limited by methodological aspects. Although longitudinal studies in this field could have been useful in explaining a causal relationship, they are problematic due to the prolonged period of observation and high risk of panel attrition $[19,25]$. In this case, retrospective studies are applied despite their limitations, such as lack of possibility to establish cause and effect or risk of recall bias [3,4,20-24]. Another problem results from the fact that there are currently no adequate tools to measure diverse childhood feeding experiences of adults that would allow to determine the link between parental feeding practices and future eating behaviors among people from different cultural groups $[4,20,22]$.

The aim of the study was two-fold: (1) to adapt the original version of the Comprehensive Feeding Practices Questionnaire (CFPQ) to measure recollections of parental feeding practices in childhood and check some of its psychometric properties, and (2) to determine a relationship between those practices recollected by adults with their current food choices. We hypothesize that some of the PFP (e.g., pressure, emotional feeding, and control) may be associated with greater intake of sweets and salty snacks in adulthood, whereas other PFP (e.g., teaching about nutrition, encouragement, modeling, and involvement) may be related to lower intake of sweets and salty snacks and higher intake of fruit and vegetables in adulthood. The findings of this study will contribute to a better understanding of the relationship between childhood experiences related to selected PFP and food choices, both favorable and adverse, in adulthood. We believe that the adopted tool would be useful for further investigation of the role of childhood food experiences when explaining eating behaviors in adulthood.

\section{Materials and Methods}

\subsection{Study Design and Sample Collection}

Data were collected in February 2020 through a cross-sectional quantitative survey. The questionnaire was administered to participants twice over a two-week interval to estimate the test-retest reliability. Recruitment and data collection were conducted by a professional market research agency using the CAWI (Computer-Assisted Web Interview) technique. The study sample was recruited from an e-panel counting around 60,000 registered individuals. Only people aged 18-65 years old were included in the study. Quota controls including gender, age, place of residence, and region were set to obtain a representative sample of the Polish population. The study involved 500 participants. All participants gave voluntary consent to participate in both parts of the study in the form of a written informed consent. As 57 people did not respond to the invitation sent after two weeks to re-participate in the study, the final sample consisted of 443 participants.

\subsection{Feeding Practices}

The Comprehensive Feeding Practices Questionnaire (CFPQ) [26] was designed as a parent-report measure of feeding practices in children aged 2-8 years. It contains items distributed into 12 subscales ("Encourage Balance and Variety", "Environment", "Involve- 
ment", “Modeling”, “Monitoring", “Teaching About Nutrition", “Emotion Regulation”, "Food as Reward", "Pressure", "Child Control", "Restriction for Health", and "Restriction for Weight Control"). In the study, a modified version of CFPQ (mCFPQ) was developed to enable retrospective reports of child feeding practices among adults, for example, we use" My parents encouraged me to eat less so I won't get fat" instead of "I encourage my child to eat less so he/she won't get fat" from the original version of the CFPQ. Respondents were asked to report how frequently different situations took place in their childhood, using a 6-point scale: 1: "never", 2: "rarely", 3: "sometimes", 4: "mostly", 5: "always", 6: "I don't remember". Moreover, they related to the sentences describing family habits from the period of their childhood using a 6-point scale: 1: "disagree", 2: "slightly disagree", 3: "neither agree nor disagree", 4: "slightly agree", 5: "agree", 6: "I don't remember". The answer "I don't remember" was added to minimize the risk of recall errors. The mCFPQ was transculturally adapted by translating it into Polish and conducting the pre-test in the group of 89 students at the beginning of the Nutritional Sociology course. Then, for the purpose of this paper, it was translated back into English. The participants were asked to reflect on their recollections from the age between 5 and 10 years old [4]. Middle childhood was selected as it represents a stage when children become more autonomous with their eating habits. Moreover, it is more probable for adults to recall memories from this period of time rather than from the earlier childhood [20].

\subsection{Food Intake}

Intake of 5 food groups, i.e., vegetables and fruits (separately fresh and processed), fruit/vegetable or mixed juices, sweets, and salty snacks was assessed using questions derived from the Dietary Habits and Nutrition Beliefs Questionnaire (KomPAN ${ }^{\circledR}$ ) [27]. Respondents reported on their food consumption using a 6-point frequency scale ranging from 'never' (1) to 'few times a day' (6). Those categories were converted into values reflecting daily frequency of consumption for each food group (the range: 0-2 times/day) [28]. Participants were also asked how many portions of products from each food group they eat per day given that 1 portion of vegetables and fruit (fresh and processed) equals $100 \mathrm{~g}$, 1 portion of juice equals 100 milliliters, and 1 portion of sweets and salty snacks equals $50 \mathrm{~g}$. Examples of the portion sizes were added for each question. Food intake was calculated for each food group by multiplying daily frequency of consumption and amounts of portions consumed.

\subsection{Statistical Analysis}

Frequency analysis was performed to present sociodemographic characteristics of the study sample.

The Q-sorting procedure was used for testing the discriminant validity concerning a substantive and a structural component of construct validity [29]. This procedure helps to separate items in a multi-dimensional construct and to eliminate items that do not discriminate well between categories of items [30]. Both exploratory and confirmatory methods were applied. Since the original factor structure of CFPQ [26] was not replicated, exploratory factor analysis (EFA) was conducted. Items from mCFPQ were treated as ordinal. The following criteria were selected to determine the final number of factors: components with an eigenvalue of 1 , a scree plot test, and the interpretability of the factors. Information sources with factor loadings of at least 0.5 were taken into account. The factorability of the data was confirmed with the Kaiser-Meyer-Olkin (KMO) measure of sampling adequacy and Bartlett's test of sphericity. The internal consistency of items within each identified factor was tested using Cronbach's alpha, with values higher than 0.70 considered acceptable. The Kolmogorov-Smirnov test was used to test the normality of each factor. As distributions were found to be non-normal, Spearman's correlations were applied to check for overlap between factors, given that correlation values $r \geq 0.85$ are indicative of a strong overlap [31]. 
To evaluate an instruments' discrimination capability, the relationships between the identified subscales (factors) and selected food products' intake were applied [29]. MannWhitney's test was used to compare mean values of each identified factor within the intake of five food groups, including (1) sweets and salty snacks, (2) fresh fruits and vegetables, (3) processed fruits and vegetables, (4) vegetable, fruit, and mixed juices, and (5) total fruits and vegetables. Within each group of food products, two categories of intake were identified using median value, i.e., "low" intake—below median, and "high" intake—above median.

Assessment of test-retest reliability was conducted by calculating interclass correlation coefficients (ICC) for each identified factor (subscale). ICC values for subscales greater than 0.40 were considered reliable.

Statistical analysis was conducted using IBM SPSS Statistics for Windows, version 26.0 (IBM Corp, Armonk, NY, USA).

\section{Results}

\subsection{Characteristics of the Study Sample}

Characteristics of the study sample are presented in Table 1. Mean age of participants was 42.4 years $( \pm 13.0$ standard deviation (SD)).

Table 1. Socio-demographic characteristics of the study sample.

\begin{tabular}{|c|c|c|}
\hline & $n^{*}$ & $\%$ \\
\hline \multicolumn{3}{|l|}{ Gender } \\
\hline Women & 224 & 50.6 \\
\hline Men & 219 & 49.4 \\
\hline \multicolumn{3}{|l|}{ Age (in years) } \\
\hline $18-24$ & 40 & 9 \\
\hline $25-39$ & 149 & 33.6 \\
\hline $40-54$ & 142 & 32.1 \\
\hline $55-65$ & 112 & 25.3 \\
\hline \multicolumn{3}{|l|}{ Education } \\
\hline Primary & 68 & 15.3 \\
\hline Lower secondary & 107 & 24.2 \\
\hline Upper secondary & 156 & 35.2 \\
\hline Higher (e.g., BSc, MSc) & 112 & 25.3 \\
\hline \multicolumn{3}{|l|}{ Place of residence } \\
\hline Village & 163 & 36.8 \\
\hline $\begin{array}{l}\text { Town below 20,000 } \\
\text { inhabitants }\end{array}$ & 54 & 12.2 \\
\hline $\begin{array}{l}\text { Town between } 20,000 \text { and } \\
100,000 \text { inhabitants }\end{array}$ & 82 & 18.5 \\
\hline City over 100,000 inhabitants & 144 & 32.5 \\
\hline
\end{tabular}

${ }^{*} n$-number of participants.

\subsection{Structure of Modified Comprehensive Feeding Practices Questionnaire ( $m C F P Q$ )}

Exploratory factors analysis revealed a factor structure consisting of 5 subscales, which were named as: "Restrictions" (13 items), "Healthy Eating Guidance" (9 items), "Pressure and Food Reward" (6 items), "Monitoring" (5 items), and "Child Control" (6 items). The factor-loadings, Cronbach's alphas, and \% of variance explained are presented in Table 2. The KMO value was found to be 0.965 , and Bartlett's test was significant at $p<0.0001$ [31]. Loadings equal to 0.50 or higher were used to identify the components of the factors. Out of 49 original items, 13 were excluded ( 3 items-“Restriction for Health", 2 items-"Emotion Regulation", 2 items-“Environment", 2 items-“Modeling", 1 item-“Teaching about 
Nutrition"). It resulted in a 39-item questionnaire (Table 2), which suggested name is Adults' Memories of Feeding in Childhood (AMoFiC).

Table 2. Factors and items included in the modified Comprehensive Feeding Practices Questionnaire (mCFPQ).

\begin{tabular}{|c|c|c|}
\hline Factors (Subscales) and Items & Factor Loadings ** & $\begin{array}{l}\text { Original Factor } \\
\quad \text { (CFPQ) }\end{array}$ \\
\hline \multicolumn{3}{|l|}{ Factor 1-Restrictions } \\
\hline $18 .^{*}$ My parents took care of me not eating too many high-fat foods. & 0.595 & $\begin{array}{l}\text { Restriction for } \\
\text { Weight Control }\end{array}$ \\
\hline 27. My parents encouraged me to eat less so I won't get fat. & 0.778 & $\begin{array}{l}\text { Restriction for } \\
\text { Weight Control }\end{array}$ \\
\hline 29. My parents gave me small helpings of food to control my body weight. & 0.769 & $\begin{array}{l}\text { Restriction for } \\
\text { Weight Control }\end{array}$ \\
\hline 31. My parents discussed with me the nutritional value of foods. & 0.664 & $\begin{array}{l}\text { Teaching about } \\
\text { Nutrition }\end{array}$ \\
\hline $\begin{array}{l}\text { 33. If I ate more at one meal, my parents tried to decrease my food helpings at the } \\
\text { next meal. }\end{array}$ & 0.749 & $\begin{array}{l}\text { Restriction for } \\
\text { Weight Control }\end{array}$ \\
\hline 34. My parents restricted the foods that would possibly make me gain weight. & 0.688 & $\begin{array}{l}\text { Restriction for } \\
\text { Weight Control }\end{array}$ \\
\hline $\begin{array}{l}\text { 35. My parents believed that there are certain foods that I should not consume to } \\
\text { prevent weight gain. }\end{array}$ & 0.683 & $\begin{array}{l}\text { Restriction for } \\
\text { Weight Control }\end{array}$ \\
\hline 36. My parents limited sweets/desserts for me in response to bad behavior. & 0.588 & Food reward \\
\hline 40. My parents wanted to be sure that I do not eat too much of my favorite foods. & 0.557 & $\begin{array}{l}\text { Restriction for } \\
\text { Health }\end{array}$ \\
\hline $\begin{array}{l}\text { 41. My parents did not allow me to eat between meals because they didn't want me to } \\
\text { gain weight. }\end{array}$ & 0.682 & $\begin{array}{l}\text { Restriction for } \\
\text { Weight Control }\end{array}$ \\
\hline 42. My parents told me what I can and cannot eat without any explanation. $\mathbf{R}$ & 0.610 & $\begin{array}{l}\text { Teaching about } \\
\text { Nutrition }\end{array}$ \\
\hline 45. My parents have often put me on a diet to control my weight. & 0.695 & $\begin{array}{l}\text { Restriction for } \\
\text { Weight Control }\end{array}$ \\
\hline 48. My parents showed me how much they enjoy 'healthy eating'. & 0.553 & Modeling \\
\hline Cronbach's Alpha & 0.947 & \\
\hline$\%$ variance explained & 41.5 & \\
\hline \multicolumn{3}{|l|}{ Factor 2-Healthy Eating Guidance } \\
\hline 14. Most of the foods that my parents kept in the house were 'healthy'. & 0.610 & Environment \\
\hline 15. My parents involved me in planning family meals. & 0.571 & Involvement \\
\hline 20. My parents allowed me to help prepare family meals. & 0.740 & Involvement \\
\hline 22. As a child, I had access to many 'healthy foods' at each meal. & 0.687 & Environment \\
\hline 24. My parents encouraged me to try new foods. & 0.693 & $\begin{array}{c}\text { Encourage Balance } \\
\text { and Variety }\end{array}$ \\
\hline 26. My parents told me that 'healthy food' tastes good. & 0.552 & $\begin{array}{c}\text { Encourage Balance } \\
\text { and Variety }\end{array}$ \\
\hline 32. My parents encouraged me to participate in grocery shopping. & 0.553 & Involvement \\
\hline 38. My parents encouraged me to eat a variety of foods. & 0.702 & $\begin{array}{c}\text { Encourage Balance } \\
\text { and Variety }\end{array}$ \\
\hline 44. My parents modelled healthy eating for me by eating healthy foods themselves. & 0.562 & Modeling \\
\hline Cronbach's Alpha & 0.902 & \\
\hline$\%$ variance explained & 6.0 & \\
\hline
\end{tabular}


Table 2. Cont.

\begin{tabular}{|c|c|c|}
\hline Factors (Subscales) and Items & Factor Loadings ** & $\begin{array}{l}\text { Original Factor } \\
\text { (CFPQ) }\end{array}$ \\
\hline \multicolumn{3}{|l|}{ Factor 3-Pressure and Food Reward } \\
\hline 17. My parents always insisted on finishing everything I had on the plate. & 0.663 & Pressure \\
\hline 19. My parents offered me my favorite foods in exchange for good behavior. & 0.587 & Food reward \\
\hline 23. My parents offered me sweets as a reward for good behavior. & 0.610 & Food reward \\
\hline 30. My parents insisted that I eat even though I told them that I'm not hungry. & 0.664 & Pressure \\
\hline 39. If I ate a small helping, my parents tried to get me to eat more. & 0.683 & Pressure \\
\hline 49. After finishing a meal, my parents tried to get me to eat more, even a bite of food. & 0.617 & Pressure \\
\hline Cronbach's Alpha & 0.860 & \\
\hline$\%$ variance explained & 4.9 & \\
\hline \multicolumn{3}{|l|}{ Factor 4-Monitoring } \\
\hline 1. Did your parents pay attention to the sweets that you were eating as a child? & 0.742 & Monitoring \\
\hline 2. Did your parents pay attention to the salty snacks that you were eating as a child? & 0.729 & Monitoring \\
\hline 3. Did your parents pay attention to the high-fat foods that you were eating as a child? & 0.582 & Monitoring \\
\hline $\begin{array}{l}\text { 4. Did your parents pay attention to the sugary drinks that you were drinking as } \\
\text { a child? }\end{array}$ & 0.752 & Monitoring \\
\hline 13. Did your parents encourage you to eat healthy foods before unhealthy ones? & 0.635 & $\begin{array}{l}\text { Encourage Balance } \\
\text { and Variety }\end{array}$ \\
\hline Cronbach's Alpha & 0.862 & \\
\hline$\%$ variance explained & 4.9 & \\
\hline \multicolumn{3}{|l|}{ Factor 5-Child Control } \\
\hline 5. Did your parents let you consume everything you wanted? & 0.720 & Child Control \\
\hline $\begin{array}{l}\text { 6. Did your parents let you choose the foods you wanted from what was being served } \\
\text { for dinner? }\end{array}$ & 0.602 & Child Control \\
\hline $\begin{array}{l}\text { 7. Did your parents give you something to eat or drink as a first thing when you } \\
\text { got fussy? }\end{array}$ & 0.566 & $\begin{array}{l}\text { Emotion } \\
\text { Regulation }\end{array}$ \\
\hline $\begin{array}{l}\text { 10. Did your parents make something else when you did not like what was } \\
\text { being served? }\end{array}$ & 0.553 & Child Control \\
\hline 11. Did you have access to snacks throughout the day? & 0.694 & Child Control \\
\hline $\begin{array}{l}\text { 12. Did your parents allow you to leave the table when you were full even when the } \\
\text { rest of the family was not done eating? }\end{array}$ & 0.592 & Child Control \\
\hline Cronbach's Alpha & 0.787 & \\
\hline$\%$ variance explained & 2.7 & \\
\hline$\%$ total variance explained & 59.4 & \\
\hline \multicolumn{3}{|l|}{ Excluded items: } \\
\hline $\begin{array}{l}\text { 8. Did your parents give you something to eat or drink when you were bored even } \\
\text { though they knew you were not hungry? }\end{array}$ & - & $\begin{array}{l}\text { Emotion } \\
\text { Regulation }\end{array}$ \\
\hline $\begin{array}{l}\text { 9. Did your parents give you something to eat or drink when you were upset even } \\
\text { though they knew you were not hungry? }\end{array}$ & - & $\begin{array}{l}\text { Emotion } \\
\text { Regulation }\end{array}$ \\
\hline 16. There were a lot of salty snacks in my parents' house. $\mathbf{R}$ & - & Environment \\
\hline
\end{tabular}


Table 2. Cont.

\begin{tabular}{|c|c|c|}
\hline Factors (Subscales) and Items & Factor Loadings ** & $\begin{array}{l}\text { Original Factor } \\
\quad \text { (CFPQ) }\end{array}$ \\
\hline $\begin{array}{l}\text { 21. If my parents did not control my eating, I would have eaten more of my } \\
\text { favorite foods. }\end{array}$ & - & $\begin{array}{l}\text { Restriction for } \\
\text { Health }\end{array}$ \\
\hline 25. My parents discussed with me why 'eating healthy' is important. & - & $\begin{array}{l}\text { Teaching about } \\
\text { Nutrition }\end{array}$ \\
\hline $\begin{array}{l}\text { 28. If my parents did not control my eating, I would have eaten more } \\
\text { 'unhealthy foods'. }\end{array}$ & - & $\begin{array}{l}\text { Restriction for } \\
\text { Health }\end{array}$ \\
\hline 37. My parents kept a lot of sweets in the house. $\mathbf{R}$ & - & Environment \\
\hline 43. My parents wanted to be sure that I did not eat too many sweets. & - & $\begin{array}{l}\text { Restriction for } \\
\text { Health }\end{array}$ \\
\hline 47. My parents were enthusiastic about 'healthy eating'. & - & Modeling \\
\hline $\begin{array}{l}\text { 46. My parents ate 'healthy foods' in front of me even if they were not their } \\
\text { favorite ones. }\end{array}$ & - & Modeling \\
\hline
\end{tabular}

* Number of statement from original CFPQ; ** correlation coefficient; items 1-13 utilize a 5-point scale: 1-"never"; 2-"rarely"; 3"sometimes"; 4-“mostly"; 5-“always"; items 14-49 utilize a 5-point scale: 1-“disagree"; 2-"slightly disagree"; 3-“" neither agree nor disagree"; 4-"slightly agree"; 5-agree"; items marked with $\mathbf{R}$ were reverse coded.

Table 3 presents Spearman's correlations between identified factors. No significant correlations were found between variables.

Table 3. Spearman's correlations (rho) between identified factors.

\begin{tabular}{|c|c|c|c|c|c|}
\hline \multirow[b]{2}{*}{ Identified Factors } & \multicolumn{5}{|c|}{ Identified Factors } \\
\hline & Restrictions & $\begin{array}{c}\text { Healthy Eating } \\
\text { Guidelines }\end{array}$ & $\begin{array}{l}\text { Pressure and Food } \\
\text { Reward }\end{array}$ & Monitoring & Child Control \\
\hline Restrictions & 1.000 & $\begin{array}{c}-0.033 \\
(p=0.490)\end{array}$ & $\begin{array}{c}0.040 \\
(p=0.400)\end{array}$ & $\begin{array}{c}0.048 \\
(p=0.317)\end{array}$ & $\begin{array}{c}0.007 \\
(p=0.878)\end{array}$ \\
\hline $\begin{array}{l}\text { Healthy Eating } \\
\text { Guidance }\end{array}$ & - & 1.000 & $\begin{array}{c}0.022 \\
(p=0.642)\end{array}$ & $\begin{array}{c}0.013 \\
(p=0.786)\end{array}$ & $\begin{array}{c}-0.059 \\
(p=0.213)\end{array}$ \\
\hline $\begin{array}{l}\text { Pressure and Food } \\
\text { Reward }\end{array}$ & - & - & 1.000 & $\begin{array}{c}0.011 \\
(p=0.821)\end{array}$ & $\begin{array}{c}0.007 \\
(p=0.890)\end{array}$ \\
\hline Monitoring & - & - & - & 1.000 & $\begin{array}{c}0.032 \\
(p=0.505)\end{array}$ \\
\hline Child Control & - & - & - & - & 1.000 \\
\hline
\end{tabular}

$p$-level of significance.

3.3. The Relationships between the Subscales of the Adults' Memories of Feeding in Childhood (AMoFiC) and Food Consumption

Fresh fruits and vegetables were consumed at least once a day, $46 \%$ and $33.6 \%$, respectively (Table 4 ). The majority of respondents consumed processed fruits and vegetables less than once a day $(91.6 \%$ and $83.3 \%$, respectively). Less than $1 / 5$ of the study sample consumed vegetable, fruit, and mixed juices at least once a day. Over $1 / 5$ of participants ate sweets at least once a day, while $7.2 \%$ ate salty snacks with such frequency. Fresh fruits were the most consumed food $(2.0 \pm 2.3$ portions per day), whereas vegetable, fruit, and mixed juices were the least consumed foods $(0.1 \pm 1.6$ portions per day). 
Table 4. Food consumption in the study sample.

\begin{tabular}{|c|c|c|c|c|c|}
\hline & \multicolumn{2}{|c|}{ Frequency Consumption (\%) } & \multicolumn{2}{|c|}{ Number of Portions a Day (\%) } & \multirow{2}{*}{$\begin{array}{c}\text { Number of } \\
\text { Portions a Day } \\
(\text { mean } \pm \text { SD) }\end{array}$} \\
\hline & $\begin{array}{c}\text { Less Than Once a } \\
\text { Day }\end{array}$ & $\begin{array}{c}\text { At Least Once a } \\
\text { Day }\end{array}$ & $\begin{array}{c}\text { Less Than } 1 \\
\text { Portion }\end{array}$ & At Least 1 Portion & \\
\hline Fresh fruits & 54.0 & 46.0 & 8.1 & 91.9 & $2.0 \pm 2.3$ \\
\hline Processed fruits & 91.6 & 8.4 & 30.2 & 69.8 & $0.5 \pm 1.1$ \\
\hline Fresh vegetables & 66.4 & 33.6 & 13.1 & 86.9 & $1.7 \pm 2.2$ \\
\hline $\begin{array}{l}\text { Processed } \\
\text { vegetables }\end{array}$ & 83.3 & 16.7 & 8.8 & 91.2 & $1.0 \pm 1.4$ \\
\hline $\begin{array}{l}\text { Vegetable, fruit, } \\
\text { and mixed juices }\end{array}$ & 85.6 & 14.4 & 25.1 & 74.9 & $0.1 \pm 1.6$ \\
\hline Sweets & 78.8 & 21.2 & 20.5 & 79.5 & $1.0 \pm 0.2$ \\
\hline Salty snacks & 92.8 & 7.2 & 10.4 & 89.6 & $0.7 \pm 1.3$ \\
\hline
\end{tabular}

$\mathrm{SD}$-standard deviation; * number of portions a day including daily frequency consumption.

Results of discriminant capability of the AMoFiC are presented in Table 5. Higher intake of sweets and salty snacks in adulthood was associated with higher scores for feeding practices in childhood included in "Pressure and Food Reward" and "Child Control" factors. Higher intake of fresh fruits and vegetables in adulthood was associated with higher scores for parental feeding practices included in "Restrictions", "Healthy Eating Guidance", and "Monitoring" factors. Higher intake of processed fruits and vegetables in adulthood was associated with higher scores for parental feeding practices included in "Healthy Eating Guidance" and "Monitoring" factors. At the same time, consumption of vegetable, fruit, and mixed juices was positively associated with scores for all identified factors. However, total consumption of fruits and vegetables was associated positively with parental feeding practices included in "Healthy Eating Guidance" and "Monitoring".

Table 5. Discriminant capability for the Adults' Memories of Feeding in Childhood using selected food products intake.

\begin{tabular}{|c|c|c|c|c|c|}
\hline & \multicolumn{5}{|c|}{ Factors (Subscales) } \\
\hline & $\begin{array}{l}\text { Restrictions } \\
\text { (mean } \pm \text { SD) }\end{array}$ & $\begin{array}{c}\text { Healthy Eating } \\
\text { Guidance } \\
\text { (mean } \pm \text { SD) }\end{array}$ & $\begin{array}{l}\text { Pressure and } \\
\text { Food Reward } \\
(\text { mean } \pm \text { SD) }\end{array}$ & $\begin{array}{l}\text { Monitoring } \\
\text { (mean } \pm \mathrm{SD} \text { ) }\end{array}$ & $\begin{array}{l}\text { Child Control } \\
\text { (mean } \pm \text { SD) }\end{array}$ \\
\hline \multicolumn{6}{|l|}{ Sweets and salty snacks } \\
\hline Low intake ${ }^{\mathrm{a}}(\mathrm{M} \leq 0.8$ portion a day $)$ & $2.3 \pm 1.0$ & $3.0 \pm 1.0$ & $2.6 \pm 1.0 * *$ & $2.6 \pm 1.1$ & $2.5 \pm 0.9 * * *$ \\
\hline High intake $^{\mathrm{a}}(\mathrm{M}>0.8$ portion a day $)$ & $2.4 \pm 1.1$ & $3.1 \pm 0.9$ & $2.8 \pm 0.9 * *$ & $2.7 \pm 1.0$ & $2.8 \pm 0.8^{* * *}$ \\
\hline \multicolumn{6}{|l|}{ Fresh fruits and vegetables } \\
\hline Low intake ( $\mathrm{M} \leq 2.0$ portion a day) & $2.3 \pm 0.9 *$ & $2.9 \pm 0.8^{* *}$ & $2.6 \pm 0.9$ & $2.6 \pm 1.0 *$ & $2.7 \pm 0.8$ \\
\hline High intake $(\mathrm{M}>2.0$ portion a day) & $2.5 \pm 1.1 *$ & $3.2 \pm 1.0^{* *}$ & $2.7 \pm 1.1$ & $2.8 \pm 1.1^{*}$ & $2.8 \pm 0.9$ \\
\hline \multicolumn{6}{|l|}{ Processed fruits and vegetables } \\
\hline Low intake ( $\mathrm{M} \leq 1.0$ portion a day) & $2.3 \pm 1.0$ & $2.9 \pm 1.0 *$ & $2.6 \pm 1.0$ & $2.5 \pm 1.0^{* * *}$ & $2.6 \pm 0.8$ \\
\hline High intake $(\mathrm{M}>1.0$ portion a day) & $2.4 \pm 1.0$ & $3.1 \pm 0.9 *$ & $2.8 \pm 0.9$ & $2.9 \pm 1.0^{* * *}$ & $2.8 \pm 0.9$ \\
\hline \multicolumn{6}{|l|}{ Vegetable, fruit, and mixed juices } \\
\hline Low intake ( $\mathrm{M} \leq 0.3$ portion a day) & $2.2 \pm 0.9^{* * *}$ & $2.9 \pm 0.9^{* * *}$ & $2.5 \pm 0.9^{* * *}$ & $2.5 \pm 1.0^{* * *}$ & $2.5 \pm 0.8^{* * *}$ \\
\hline High intake $(\mathrm{M}>0.3$ portion a day) & $2.6 \pm 1.0^{* * *}$ & $3.3 \pm 0.9^{* * *}$ & $2.9 \pm 1.0 * * *$ & $2.9 \pm 1.0^{* * *}$ & $2.9 \pm 0.9 * * *$ \\
\hline \multicolumn{6}{|l|}{ Total fruits and vegetables } \\
\hline Low intake ( $\mathrm{M} \leq 4.0$ portion a day) & $2.3 \pm 0.9$ & $2.9 \pm 0.8^{* *}$ & $2.6 \pm 0.9$ & $2.6 \pm 1.0 *$ & $2.6 \pm 0.8$ \\
\hline High intake $(\mathrm{M}>4.0$ portion a day) & $2.5 \pm 1.1$ & $3.2 \pm 1.0 * *$ & $2.8 \pm 1.0$ & $2.8 \pm 1.1 *$ & $2.8 \pm 0.9$ \\
\hline
\end{tabular}

Assessment of test-retest reliability revealed the following ICC values for each newly identified factor: "Restrictions" - 0.674, "Healthy Eating Guidance" -0.668 , "Pressure and Food Reward" -0.651 , "Monitoring" -0.634 , and "Child Control" -0.559. 


\section{Discussion}

So far, the attempts to adopt the Comprehensive Feeding Practices Questionnaire (CFPQ) to measure adults' childhood recollections were made, however, the study groups consisted solely of students and only selected subscales and questions from the original CFPQ were chosen $[4,20,22]$. We adopted a full version of the questionnaire. As a result of the exploratory factor analysis, we obtained a 39-item Adults' Memories of Feeding in Childhood (AMoFiC) questionnaire with satisfactory psychometric parameters, including acceptable Cronbach's alpha values, test-retest reliability, discriminant validity, and lack of statistically significant correlations between newly identified factors. However, psychometric parameters of this measure should still be confirmed in future research among different study groups. Further testing of its discriminant and convergent validity is also required [32].

We confirmed the hypothesis that specific factors associated with feeding practices in childhood might determine food consumption in adulthood. Results provide evidence that greater intensity of practices characteristic for "Pressure and Food Reward" and "Child Control" might favor higher intake of sweets and salty snacks. Forced consumption in response to fussy eating may not only deepen food aversion, but also persist into adulthood, leading to lower intake of target foods and higher intake of unfavorable foods [22,24]. Rewarding with food to influence children's behavior or as a mood enhancer might result in emotional eating in adulthood $[4,20]$. Emotional eating is characterized by eating mostly highly palatable foods, such as processed, high-energy, high-fat, and high-sugar food products, which may result in weight gain [33].

The study results suggest that parental control might be related to unhealthy eating behaviors in adulthood. Pressure to eat and restrictive feeding (overt control) can be easily detected by the children, whereas other practices such as buying healthy food and avoiding places selling unfavorable foods, being examples of covert control, are less likely to be recognized. Moderate control, including covert control, is believed to support healthier eating behaviors in children [1]. The AMoFiC "Child Control" factor did not take into account those two types of control separately. Moreover, after exploratory factor analysis, items describing "Environment" and "Modeling" factors, which could have been interpreted as examples of covert control, were excluded. Further research to determine if both covert and overt control might predispose to more frequent consumption of unfavorable foods is needed.

As expected, "Healthy Eating Guidance" including setting a healthy environment, modeling food behaviors, and allowing child to participate in the process of choosing, buying, and preparing meals, was associated with higher consumption of fresh fruits and vegetables [32]. Similarly, "Monitoring" turned out to be associated with higher consumption of fresh fruits and vegetables. Practices associated with monitoring are based on observing children's behavior without turning into intrusive of restrictive methods [1]. Whereas restrictive feeding might promote unhealthy eating behaviors. Foods which are limited might be viewed as a "forbidden fruit", leading to excessive food preoccupation. Desire to eat those products in larger quantity when they are available might persist into adulthood, increasing chances of disordered eating, including emotional eating and binge eating [4]. Nevertheless, our study did not confirm the relationship between restrictions applied in childhood and high consumption of sweets and salty snacks in adulthood. One possible explanation might be that the intake of those unfavorable foods was fairly low among the study group. Moreover, recollections on eating sweets in childhood might have been associated with being rewarded for good behavior [23], which was confirmed by our results. "Restrictions" factor was found to be linked with higher fresh fruits and vegetables consumption [34]. However, promoting restrictive practices to increase children's intake of those favorable food products cannot be accepted as parents may experience resistance while limiting healthy foods for their child. Nonetheless, the role of parental restrictive feeding on the intake of those foods in adulthood should be further studied. 
The current study provided evidence that intake of certain food groups in adulthood might be determined by parental feeding practices in childhood. More research with the use of $\mathrm{AMoFiC}$ and other tools is required to confirm this relationship with regard to the intake of both healthy and unhealthy food products and the usefulness of the tool developed in the current study. The previous research did not analyze the associations between parental feeding practices in childhood with food intake in adulthood, yet it examined how childhood experiences are correlated with eating styles in adulthood [4,20,22]. Thus, further studies concerning food consumption but also eating styles in adulthood are needed.

\section{Strengths and Limitations}

To our knowledge, this study is the first to use a full version of the Comprehensive Feeding Practices Questionnaire (CFPQ) in adults to measure their childhood recollections. Moreover, our study attempted to fill the knowledge gap on the impact of childhood experiences associated with feeding practices on future food choices. The strength of this study is also the use of a representative study sample in terms of age, gender, education level, and place of residence, thus the outcomes can be generalized to the population.

Despite the mentioned advantages, the study has certain limitations. The findings of the study were based on retrospective self-reports, which could have been biased, for example by imprecise recollections or social-desirability bias [3]. Secondly, the data were collected among Polish adults, hence the results cannot be generalized to other populations due to the differences associated with ethnicity or socioeconomic status [20]. Moreover, as mentioned in the Introduction Section, the cross-sectional design of this study does not allow to find a causal relationship. Additionally, the measure of childhood recollections in adults used in our study (mCFPQ) has been rarely used in the previous studies, thus there is a need for future research to assess its psychometric properties and confirm its validity. We assessed test-retest reliability of the questionnaire and although reliability is an important aspect of measurement, it is not sufficient to confirm the validity of the test [35]. Moreover, there is no general consensus on what constitutes a good ICC [36,37]. Thus, further studies are required to provide insight into the test-retest reliability and validity of the questionnaire, especially including convergent validity.

Despite these limitations, the findings of this study may contribute to a better understanding of the relationship between childhood experiences related to selected parental feeding practices and food choices, both favorable and adverse, in adulthood.

\section{Conclusions}

The current study did not manage to confirm the original structure of the Comprehensive Feeding Practices Questionnaire (CFPQ) with the use of its modified version (mCFPQ); however, a newly developed shortened tool (AMoFiC) demonstrated good psychometric properties, proving that it might be used to measure retrospective reports of children's feeding practices in adults, however further research to confirm its properties is still needed. The study results showed that childhood experiences might favor certain dietary patterns in adulthood, both adverse (snacking on sweets and salty snacks) and favorable (consumption of fruits and vegetables). Future research should focus on the impact of parental feeding practices on other dietary habits and diet quality and assess their relationship with eating styles.

Author Contributions: Conceptualization, A.M. and M.J.-Z.; methodology, A.M. and M.J.-Z.; validation, A.M. and M.J.-Z.; formal analysis, M.J.-Z.; resources, M.J.-Z.; data curation, A.M. and M.J.-Z.; writing-original draft preparation, A.M.; writing—review and editing, A.M. and M.J.-Z.; visualization, A.M.; supervision, M.J.-Z.; project administration, M.J.-Z.; funding acquisition, M.J.-Z. All authors have read and agreed to the published version of the manuscript.

Funding: The research was financed by the Polish Ministry of Science and Higher Education with funds from the Institute of Human Nutrition Sciences, Warsaw University of Life Sciences (WULS), for scientific research. 
Institutional Review Board Statement: The study was conducted according to the guidelines of the Declaration of Helsinki and approved by the Ethics Committee of the Institute of Human Nutrition Sciences, Warsaw University of Life Sciences, in Poland (Resolution No. 02/2020).

Informed Consent Statement: Informed consent was obtained from all subjects involved in the study.

Data Availability Statement: The data presented in this study are available on request from the corresponding author.

Acknowledgments: Thanks are expressed to the participants for their contributions to the study.

Conflicts of Interest: The authors declare no conflict of interest.

\section{References}

1. Scaglioni, S.; De Cosmi, V.; Ciappolino, V.; Parazzini, F.; Brambilla, P.; Agostoni, C. Factors Influencing Children's Eating Behaviours. Nutrients 2018, 10, 706. [CrossRef]

2. Kiefner-Burmeister, A.; Hinman, N. The Role of General Parenting Style in Child Diet and Obesity Risk. Curr. Nutr. Rep. 2020, 9, 14-30. [CrossRef]

3. Williams, N.; Dev, D.; Hankey, M.; Blitch, K. Role of food preoccupation and current dieting in the associations of parental feeding practices to emotional eating in young adults: A moderated mediation study. Appetite 2017, 111, 195-202. [CrossRef] [PubMed]

4. Tan, C.; Ruhl, H.; Chow, C.; Ellis, L. Retrospective reports of parental feeding practices and emotional eating in adulthood: The role of food preoccupation. Appetite 2016, 105, 410-415. [CrossRef]

5. Bandura, A.; McClelland, D.C. Social Learning Theory (Vol. 1); Prentice Hall: Englewood Cliffs, NJ, USA, 1977.

6. Glanz, K.; Rimer, B.; Viswanath, K. Health Behavior and Health Education: Theory Research and Practice; Jossey-Bass Publishers: San Francisco, CA, USA, 2008.

7. Birch, L.; Savage, J.S.; Ventura, A. Influences on the Development of Children's Eating Behaviours: From Infancy to Adolescence. Can. J. Diet. Pract. Res. A Publ. Dietit. Can. Rev. Can. Prat. Rech. Diet. Publ. Diet. Can. 2007, 68, 1-56.

8. Russell, C.; Haszard, J.; Taylor, R.; Heath, A.; Taylor, B.; Campbell, K. Parental feeding practices associated with children's eating and weight: What are parents of toddlers and preschool children doing? Appetite 2018, 128, 120-128. [CrossRef] [PubMed]

9. Vollmer, R. Parental feeding style changes the relationships between children's food preferences and food parenting practices: The case for comprehensive food parenting interventions by pediatric healthcare professionals. J. Spec. Pediatric Nurs. 2019, 24, e12230. [CrossRef] [PubMed]

10. De Bourdeaudhuij, I.; te Velde, S.; Brug, J.; Due, P.; Wind, M.; Sandvik, C.; Maes, L.; Wolf, A.; Rodrigo, C.; Yngve, A.; et al. Personal, social and environmental predictors of daily fruit and vegetable intake in 11-year-old children in nine European countries. Eur. J. Clin. Nutr. 2007, 62, 834-841. [CrossRef] [PubMed]

11. Kremers, S.; Brug, J.; de Vries, H.; Engels, R. Parenting style and adolescent fruit consumption. Appetite 2003, 41, 43-50. [CrossRef]

12. Peters, J.; Dollman, J.; Petkov, J.; Parletta, N. Associations between parenting styles and nutrition knowledge and 2-5-year-old children's fruit, vegetable and non-core food consumption. Public Health Nutr. 2012, 16, 1979-1987. [CrossRef]

13. Hennessy, E.; Hughes, S.; Goldberg, J.; Hyatt, R.; Economos, C. Permissive Parental Feeding Behavior Is Associated with an Increase in Intake of Low-Nutrient-Dense Foods among American Children Living in Rural Communities. J. Acad. Nutr. Diet. 2012, 112, 142-148. [CrossRef]

14. Lopez, N.; Schembre, S.; Belcher, B.; O’Connor, S.; Maher, J.; Arbel, R.; Margolin, G.; Dunton, G. Parenting styles, food-related parenting practices, and children's healthy eating: A mediation analysis to examine relationships between parenting and child diet. Appetite 2018, 128, 205-213. [CrossRef]

15. Haszard, J.J.; Skidmore, P.M.; Williams, S.M.; Taylor, R.W. Associations between parental feeding practices, problem food behaviours and dietary intake in New Zealand overweight children aged 4-8 years. Public Health Nutr. 2015, 18, 1036-1043. [CrossRef] [PubMed]

16. Warkentin, S.; Mais, L.A.; Latorre, M.d.R.D.d.; de Aguiar CarrazedoTaddei, J.A. Relationships between parent feeding behaviors and parent and child characteristics in Brazilian preschoolers: A cross-sectional study. BMC Public Health 2018, 18, 704. [CrossRef]

17. Kiefner-Burmeister, A.; Hoffmann, D.; Zbur, S.; Musher-Eizenman, D. Implementation of parental feeding practices: Does parenting style matter? Public Health Nutr. 2016, 19, 2410-2414. [CrossRef] [PubMed]

18. Smith, A.D.; Sanchez, N.; Reynolds, C.; Casamassima, M.; Verros, M.; Annameier, S.K.; Melby, C.; Johnson, S.A.; Lucas-Thompson, R.G.; Shomaker, L.B. Associations of parental feeding practices and food reward responsiveness with adolescent stress-eating. Appetite 2020, 152, 104715. [CrossRef]

19. Hazzard, V.M.; Loth, K.A.; Berge, J.M.; Larson, N.I.; Fulkerson, J.A.; Neumark-Sztainer, D. Does exposure to controlling parental feeding practices during adolescence predict disordered eating behaviors 8 years later in emerging adulthood? Pediatric Obes. 2020, 15, e12709. [CrossRef] [PubMed]

20. Galloway, A.; Farrow, C.; Martz, D. Retrospective Reports of Child Feeding Practices, Current Eating Behaviors, and BMI in College Students. Obesity 2010, 18, 1330-1335. [CrossRef]

21. Branen, L.; Fletcher, J. Comparison of College Students' Current Eating Habits and Recollections of Their Childhood Food Practices. J. Nutr. Educ. 1999, 31, 304-310. [CrossRef] 
22. Ellis, J.; Galloway, A.; Webb, R.; Martz, D.; Farrow, C. Recollections of pressure to eat during childhood, but not picky eating, predict young adult eating behavior. Appetite 2016, 97, 58-63. [CrossRef] [PubMed]

23. Puhl, R.; Schwartz, M. If you are good you can have a cookie: How memories of childhood food rules link to adult eating behaviors. Eat. Behav. 2003, 4, 283-293. [CrossRef]

24. Robert Batsell, W.; Brown, A.; Ansfield, M.; Paschall, G. "You Will Eat All of That!": A retrospective analysis of forced consumption episodes. Appetite 2002, 38, 211-219. [CrossRef] [PubMed]

25. Gustavson, K.; von Soest, T.; Karevold, E.; Røysamb, E. Attrition and generalizability in longitudinal studies: Findings from a 15-year population-based study and a Monte Carlo simulation study. BMC Public Health 2012, 12, 918. [CrossRef]

26. Musher-Eizenman, D.; Holub, S. Comprehensive Feeding Practices Questionnaire: Validation of a new measure of parental feeding practices. J. Pediatr. Psychol. 2007, 32, 960-972. [CrossRef]

27. Jezewska-Zychowicz, M.; Gawecki, J.; Wadolowska, L.; Czarnocinska, J.; Galinski, G.; KollajtisDolowy, A.; Roszkowski, W.; Wawrzyniak, A.; Przybylowicz, K.; Krusinska, B.; et al. Dietary Habits and Nutrition Beliefs Questionnaire for people 15-65 years old, version 1.1.- Interviewer administered questionnaire. Chapter 1. In Dietary Habits and Nutrition Beliefs Questionnaire and the Manual for Developing of Nutritional Data; Gawecki, J., Ed.; The Committee of Human Nutrition, Polish Academy of Sciences: Olsztyn, Poland, 2018; pp. 3-20. Available online: http:/ / www.knozc.pan.pl/ (accessed on 6 November 2019).

28. Wadolowska, L.; Krusinska, B. The manual for developing nutritional data from the KomPAN ${ }^{\circledR}$ questionnaire. Chapter 3. In Dietary Habits and Nutrition Beliefs Questionnaire and the Manual for Developing Nutritional Data; Gawecki, J., Ed.; The Committee of Human Nutrition, Polish Academy of Sciences: Olsztyn, Poland, 2018; pp. 34-52. Available online: http://www.knozc.pan.pl/ (accessed on 6 November 2019).

29. Benson, J. Developing a strong program of construct validation: A test anxiety example. Educ. Meas. Issues Pract. 1998, 17, 10-17. [CrossRef]

30. Zait, A.; Bertea, P.E. Methods for Testing Discriminant Validity. Manag. Mark. J. 2011, 9, 217-224.

31. Field, A. Discovering Statistics Using SPSS, 3rd ed.; Sage Publications: London, UK, 2009.

32. Warkentin, S.; Mais, L.; Latorre, M.; Carnell, S.; Taddei, J. Validation of the comprehensive feeding practices questionnaire in parents of preschool children in Brazil. BMC Public Health 2016, 16, 1-12. [CrossRef] [PubMed]

33. Konttinen, H.; van Strien, T.; Männistö, S.; Jousilahti, P.; Haukkala, A. Depression, emotional eating and long-term weight changes: A population-based prospective study. Int. J. Behav. Nutr. Phys. Act 2019, 16, 28. [CrossRef] [PubMed]

34. Jansen, E.; Mulkens, S.; Emond, Y.; Jansen, A. From the Garden of Eden to the land of plenty: Restriction of fruit and sweets intake leads to increased fruit and sweets consumption in children. Appetite 2008, 51, 570-575. [CrossRef] [PubMed]

35. Weir, J.P. Quantifying test-retest reliability using the intraclass correlation coefficient and the SEM. J. Strength Cond. Res. 2005, 19, 231-240. [CrossRef] [PubMed]

36. Shrout, P.E. Measurement reliability and agreement in psychiatry. Stat Methods Med. Res. 1998, 7, 301-317. [CrossRef] [PubMed]

37. Schougaard, L.M.V.; de Thurah, A.; Bech, P.; Hjollund, N.H.; Christiansen, D.H. Test-retest reliability and measurement error of the Danish WHO-5 Well-being Index in outpatients with epilepsy. Health Qual. Life Outcomes 2018, 16, 175. [CrossRef] [PubMed] 